\title{
Distrofia de Fuchs: imágenes con un dispositivo móvil
}

\section{Fuchs' dystrophy: Images taken with a mobile device}

\author{
Francisco Beltrán-Díaz de la Vega y Schenny Murra-Antón*
}

Asociación para Evitar la Ceguera en México I.A.P., Ciudad de México, México

\section{Resumen}

La distrofia endotelial de Fuchs es un trastorno común caracterizado por una disfunción progresiva del endotelio corneal. Clínicamente se observan guttae centrales en la membrana de Descemet, y en etapas tardías edema corneal con bullas epiteliales. Puede ocurrir esporádicamente o ser heredada con un patrón autosómico dominante. Afecta en general a mujeres mayores de 40 años y se considera la causa más común de trasplante de córnea en todo el mundo. Se presenta el caso de un paciente de 59 años, sin antecedentes de importancia, con hallazgos típicos de distrofia endotelial de Fuchs.

Palabras clave: Distrofia endotelial de Fuchs. Pérdida de células endoteliales corneales. Enfermedades corneales. Distrofias corneales hereditarias. Endotelio corneal. Enfermedades oculares.

\section{Abstract}

Fuchs endothelial dystrophy is a common disorder characterized by progressive corneal endothelial dysfunction, clinically central guttae are observed in descemet membrane and in late stages corneal edema with epithelial bullae can occur. It can happen sporadically or be inherited in an autosomal dominant pattern. Usually, affects women over 40 years old and is considered the most common cause of corneal transplantation worldwide. We present the case of a 59-year-old male patient with no significant history with typical Fuchs endothelial dystrophy findings.

Keywords: Fuchs' endothelial dystrophy. Corneal endothelial cell loss. Corneal diseases. Corneal dystrophies, hereditary. Endothelium, corneal. Eye diseases.

Varón de 59 años que refiere disminución fluctuante de la visión de ambos ojos. Agudeza visual después de 3.5 horas de vigilia: 20/50 ojo derecho y $20 / 60$ ojo izquierdo. En las imágenes se observan guttae corneales centrales a la retroiluminación (Fig. 1 A) y con reflexión especular (Fig. 1 B y C). Las fotografías fueron capturadas con lámpara de hendidura (Modelo SL9900, CSO, Florencia, Italia) por un teléfono inteligente (Modelo iPhone 8, Apple Inc, California, USA). Para su captura, se subió el brillo de la lámpara de hendidura

Correspondencia:

*Schenny Murra-Antón Vicente García Torres 46 C.P. 04030 , Ciudad de México, México E-mail: Schennyanton@ hotmail.com DOI: 10.24875/RMO.M21000155 (http://creativecommons.org/licenses/by-nc-nd/4.0/).
Fecha de recepción: 25-05-2020 


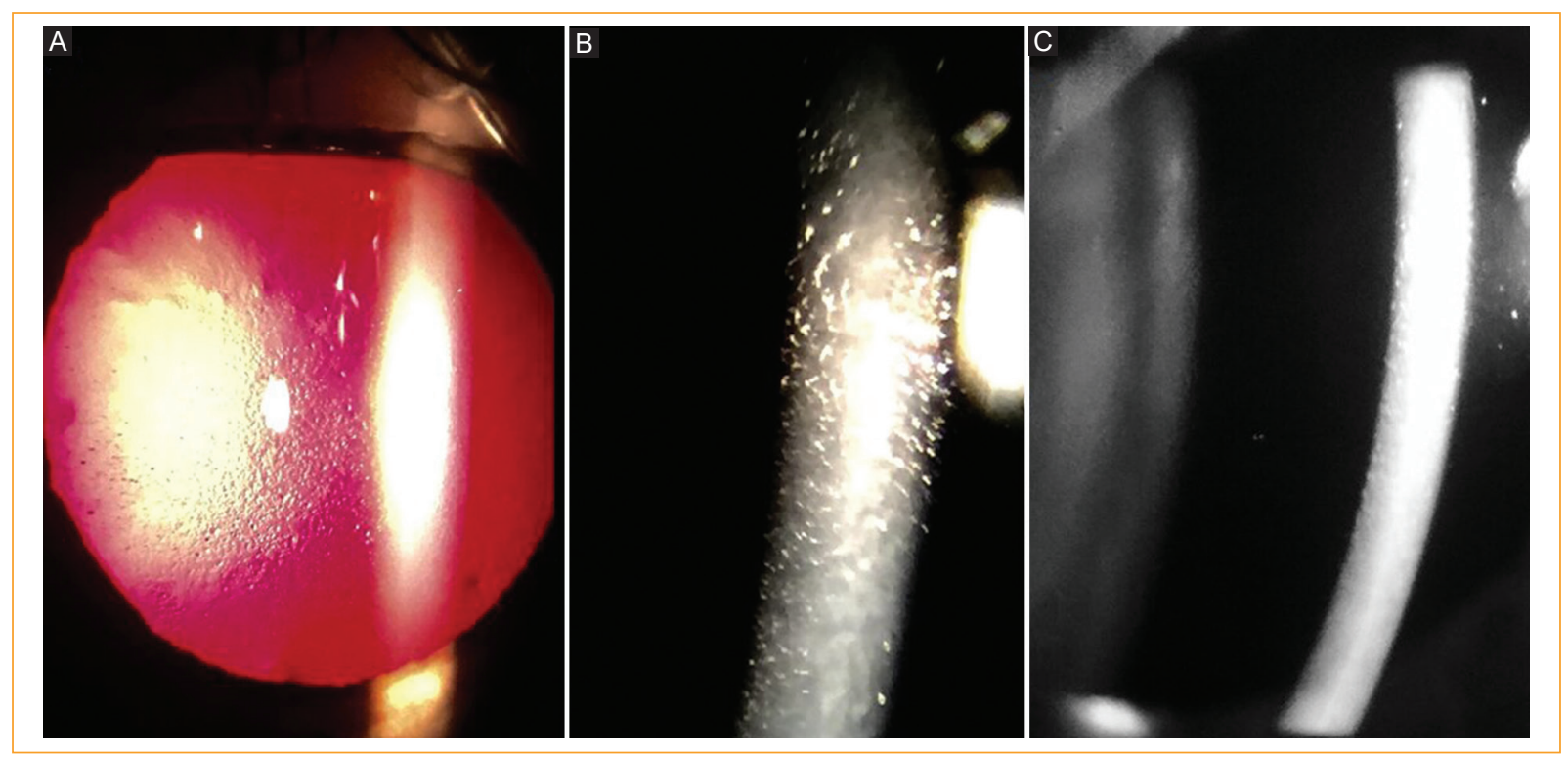

Figura 1. Fotografía con lámpara de hendidura. A: guttae corneales centrales a la retroiluminación. B y C: guttae corneales con reflexión especular.

al máximo, con magnificación a 10x, se colocó la cámara posterior del teléfono en contacto directo con el ocular y, mediante la visualización de la imagen en la pantalla del teléfono, se procedió al enfoque moviendo la lámpara en el eje $x$ utilizando el enfoque automático del teléfono como final ${ }^{1-3}$.

\section{Conflicto de intereses}

Los autores declaran no tener conflictos de intereses.

\section{Responsabilidades éticas}

Protección de personas y animales. Los autores declaran que para esta investigación no se han realizado experimentos en seres humanos ni en animales.
Confidencialidad de los datos. Los autores declaran que han seguido los protocolos de su centro de trabajo sobre la publicación de datos de pacientes.

Derecho a la privacidad y consentimiento informado. Los autores han obtenido el consentimiento informado de los pacientes y/o sujetos referidos en el artículo. Este documento obra en poder del autor de correspondencia.

\section{Bibliografía}

1. Soh Y, Kocaba V, Pinto M, Mehta J. Fuchs endothelial corneal dystrophy and corneal endothelial diseases: East meets West. Eye. 2019;34:427-41.

2. Gouranga Nanda G, Pankaj Alone D. Current understanding of the pathogenesis of Fuchs' endothelial corneal dystrophy. Mol Vis. 2019;25:295-310.

3. Matthaei M, Hribek A, Clahsen T, Bachmann B, Cursiefen C, Jun A Fuchs endothelial corneal dystrophy: clinical, genetic, pathophysiologic, and therapeutic aspects. Ann Rev Vis Sci. 2019;5:151-75. 